\title{
PENGARUH BUDAYA ORGANISASI, KOMUNIKASI DAN \\ LINGKUNGAN KERJA TERHADAP KEPUASAAN KERJA KARYAWAN UNIVERSITAS AHMAD DAHLAN YOGYAKARTA
}

\author{
Tunjung Santika Sari \\ sartikatunjung@gmail.com \\ Universitas Ahmad Dahlan \\ Utik Bidayati \\ utikbidayati@yahoo.com \\ Universitas Ahmad Dahlan
}

\begin{abstract}
ABSTRAK
This study aims to determine the effect of organizational culture, communication and work environment on job satisfaction of Ahmad Dahlan University employees. In this study the population used was faculty administration employees who have an accreditation study program totaling 65 people. The sample used was 65 respondents using the saturated sampling method. The analysis technique used is multiple regression analysis. Hypothesis testing using $t$ test shows that organizational culture has no effect on employee job satisfaction while communication and work environment influence on job satisfaction. Then through the $\mathrm{F}$ test shows that organizational culture, communication and work environment simultaneously affect job satisfaction.
\end{abstract}

Kata Kunci: Organizational Culture, Communication, Work Environment, Work Satisfaction.

\begin{tabular}{l}
\hline PENDAHULUAN \\
\cline { 2 - 2 } Semakin ketatnya persaingan \\
dalam pendidikan menuntut \\
perguruan tinggi menjaga kualitas dalam \\
meningkatkan keunggulannya agar mampu \\
bersaing dengan perguruan tinggi lainnya. \\
Selain itu universitas juga harus \\
memperhatikan kepuasaan kerja karyawan \\
sebagai tolak ukur seberapa berkualitasnya \\
mutu universitas tersebut. Ada beberapa \\
faktor yang mempengaruhi kepuasaan \\
kerja karyawan yaitu budaya organisasi, \\
komunikasi dan lingkungan kerja. Cara \\
melihat kepuasaan kerja karyawan \\
universitas harus memperhatikan budaya \\
organisasi yang sudah terbentuk, cara \\
berkomunikasi antar karyawan atau \\
karyawan dengan atasan dan universitas \\
menciptakan lingkungan kerja yang \\
nyaman bagi para karyawan. Handoko \\
Hani (2004:193) mengemukakan bahwa \\
kepuasaan kerja adalah keadaan emosional
\end{tabular}

yang menyenangkan atau tidak menyenangkan dengan mana para karyawan memandang pekerjaan mereka. Sobirin Achmad (2009:123) mengemukakan bahwa Budaya organisasi konsep budaya organisasi biisa dikatakan masih relatif baru yakni baru berkembang sekitar awal tahun 1980- an. Konsep ini, seperti diakui para teoritis organisasi, diadopsi dari konsep budaya yang terlebih dahulu berkembang pada disiplin "Gagasan, tidak peduli seberapa hebatnya, tidak berguna sebelum diteruskan dan dipahami oleh orang-orang lain. Komunikasi yang sempurna, jika ada hal semacam itu, akan2 muncul bila pikiran atau ide disampaikan sehingga gambaran mental yang dipersepsikan penerima, persis sama dengan yang dibayangkan oleh pengirim. Meskipun teorinya mudah, komunikasi yang sempurna tidak pernah dicapai dalam praktik, karena alas an yang akan kami jelaskan kemudian"(Robbins 
Stephen P, 2008:392). Nitisemo alex s (2000:183) mengemukakan bahwa Lingkungan kerja adalah segala sesuatu yang ada disekitar para pekerja yang dapat mempengaruhi dirinya dalam menjalankan tugas-tugas yang diberikan. Sedarmayanti (2001:1) mengemukakan bahwa lingkungan kerja adalah keseluruhan alat perkakas dan bahan yang dihadapi, lingkungan sekitarnya di mana seseorang bekerja, metode kerjanya, serta pengaturan kerjanya baik sebagai perseorangan maupun sebagai kelompok.

\section{Rumusan Masalah}

1. Apakah terdapat pengaruh secara parsial Budaya Organisasi terhadap kepuasaan karyawan UAD?

2. Apakah terdapat pengaruh secara parsial Komunikasi terhadap kepuasaan karyawan UAD?

3. Apakah terdapat pengaruh secara parsial Lingkungan kerja terhadap kepuasaan karyawan UAD?

4. Apakah terdapat pengaruh secara simultan antara Budaya organisasi, Komunikasi dan Lingkungan Kerja secara bersamaan terhadap Kepuasan Karyawan UAD?

\section{REVIEW LITERATUR DAN HIPOTESIS}

\section{Landasan Teori}

\section{Budaya Organisasi}

Sobirin Achmad

(2009:124)

mengemukakan bahwa Konsep budaya organisasi bias dikatakan masih relatif baru yakni baru berkembang sekitar awal tahun 1980-an. Konsep ini, seperti diakui para teoritisi organisasi, diadopsi dari konsep budaya yang terlebih dahulu berkembang pada disiplin antropologi.

Menurut Robbins, Stephen $P$ (2008:725) "Budaya menjalankan sejumlah fungsi di dalam organisasi. Pertama, budaya mempunyai peran menetapkan tapal batas; artinya, budaya menciptakan pembedaan yang jelas antara satu organisasi dan yang lain. Kedua, budaya memberikan rasa identitas ke anggota-anggota organisasi. Ketiga, budaya mempermudah timbulnya komitmen pada sesuatu yang lebih luas daripada kepentingan diri pribadi seseorang. Keempat, budaya itu meningkatkan kemantapan. Budaya merupakan perekat sosial yang membantu mempersatukan organisasi itu dengan memberikan standar-standar yang tepat mengenai apa yang harus dikatakan dan dilakukan oleh para karyawan. Akhirnya budaya berfungsi sebagai mekanisme 8 pembuat makna dan mekanisme pengendali yang memandu dan membentuk sikap serta perilaku para karyawan.

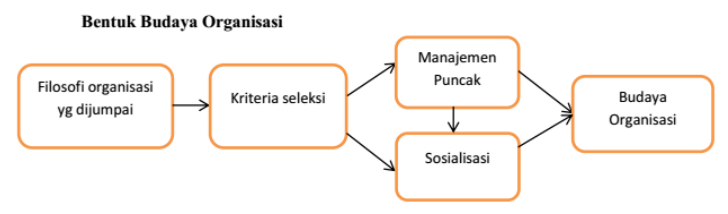

\section{Komunikasi}

"Pengertian dasar komunikasi atau dalam bahasa Inggris communication berasal dari bahasa latin communication, dan bersumber dari kata communis yang berarti sama. Sama di sini maksudnya adalah sama makna. Jadi, kalau dua orang terlibat dalam komunikasi, misalnya dalam bentuk percakapan, maka komunikasi akan terjadi atau berlangsung selama da kesamaan makna mengenai apa yang dipercakapkan. Akan tetapi, pengertian komunikasi itu minimal harus mengandung kesamaan makna antara dua pihak yang terlibat. Dikatakan minimal karena kegiataan komunikasi tidak hanya informatif, yakni agar orang lain mengerti dan tahu, tetapi juga persuasive, yaitu agar orang lain bersedia menerima suatu paham atau keyakinan, melakukan suatu perbuatan atau kegiatan, dan lain-lain." (Onong Uchjana, 2004:8). 
Model Proses Komunikasi

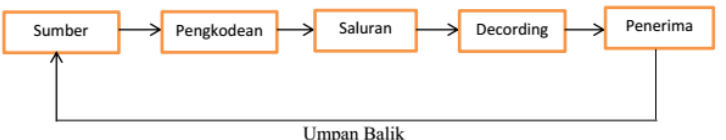

\section{Lingkungan Kerja}

Sedarmayanti

(2001:1)

mengemukakan bahwa lingkungan kerja adalah keseluruhan alat perkakas dan bahan yang dihadapi, lingkungan sekitarnya di mana seseorang bekerja, metode kerjanya, serta pengaturan kerjanya baik sebagai perseorangan maupun sebagai kelompok. Dari beberapa pendapat tersebut, disimpulkan bahwa lingkungan kerja merupakan segala sesuatu yang ada di sekita karyawan pada saat bekerja, baik yang berbentuk fisik ataupun non fisik, langsung atau tidak langsung, yang dapat mempengaruhi dirinya dan pekerjaanya saat bekerja.

\section{Jenis Lingkungan Kerja}

Sedarmayanti

mengemukakan bahwa secara garis besar, jenis lingkungan kerja terbagi menjadi 2 yakni: Lingkungan kerja fisik, dan lingkungan kerja non fisik.

1. Lingkungan kerja Fisik

Menurut Sedarmayanti (2001:21)

"Lingkungan kerja fisik adalah semua keadaan berbentuk fisik yang terdapat di sekitar tempat kerja yang dapat mempengaruhi karyawan baik secara langsung maupun secara tidak langsung)

2. Lingkungan Kerja Non Fisik

Menurut Sadarmayanti (2001:31) "Lingkungan kerja non fisik adalah semua keadaan yang terjadi yang berkaitan dengan hubungan kerja, baik hubungan dengan atasan maupun hubungan sesama rekan kerja, ataupun hubungan dengan bawahan. Lingkungan non fisik ini juga merupakan kelompok lingkungan kerja yang tidak bisa diabaikan.

\section{Kepuasan Kerja}

Handoko hani (2004:193) mengemukakan bahwa kepuasaan kerja adalah keadaan emosional yang menyenangkan atau tidak menyenangkan dengan mana para karyawan memandang pekerjaan mereka. Kepuasaan kerja mencerminkan perasaan seseorang terhadap pekerjaannya.

Menurut Robbin (2002:78)

"kepuasan kerja adalah sikap umum terhadap pekerjaan seseorang yang menunjukkan perbedaan antara jumlah penghargaan yang diterima pekerjaan dan jumlah yang mereka yakini seharusnya mereka terima) sedangkan Menurut Gibson (2000:106) mengemukakan bahwa kepuasan kerja sebagai sikap yang dimiliki para pekerja tentang pekerjaan mereka. Hal itu merupakan hasil dari persepsi mereka tentang pekerjaan. Kepuasan kerja (Job23 Satisfaction) adalah keadaan emosional karyawan yang terjadi maupun tidak terjadi titik temu antara nilai balas jasa kerja karyawan dan perusahaan atau organisasi dengan tingkat nilai balas jada yang memang diinginkan oleh karyawan yang bersangkutan (Martoyo, 2000: 142)

\section{Penelitian Terdahulu}

1. Kurniawati Dewi (2008) dengan judul Pengaruh Komunikasi terhadap Kepuasaan Kerja Karyawan pada KPRI Universitas Brawijaya Malang. Maka dapat ditarik kesimpulan yaitu:

a. Komunikasi vertical teruji berpengaruh secara signifikan terhadap Kepuasaan kerja karyawan, ditunjukan dengan nilai $t$ hitung sebesar 3,023 lebih besar dari t tabel 1,671 .

2. Suryaningsih Ni Putu Eka Putri (2013) dengan judul Pengaruh Budaya Organisasi, Komunikasi dan Lingkungan Kerja Fisik terhadap Kepuasaan Kerja Karyawan pada Ramada Bintang Bali Resort and Spa di Kuta Kabupaten Badung, kesimpulan yang dapat ditarik 
dalam penelitian ini adalah sebagai berikut::

a. Ada pengaruh positif dan signifikan secara simultan antara budaya organisasi, komunikasi dan lingkungan kerja fisik terhadap kepuasan kerja karyawan pada Ramada Bintang Bali Resort and Spa di Kuta, Kabupaten Badung.

b. Ada pengaruh positif dan signifikan secara parsial antara budaya organisasi, komunikasi dan lingkungan kerja fisik terhadap kepuasan kerja karyawan pada Ramada Bintang Bali Resort and Spa di Kuta, Kabupaten Badung.

3. ElviTrianim Purba (2016) dengan judul Pengaruh Budaya Organisasi terhadap Kepuasaan Kerja Pegawai PDAM Tirta Bina LabuahanBatu, maka kesimpulan yang dapat ditarik dalam penelitian ini adalah sebagai berikut:

a. Variabel Budaya Organisasi dengan karakteristik inovasi, detail, hasill dan individu tidak berpengaruh secara signifikan terhadap kepuasaan kerja pegawai PDAM Tirta Bina Labuhan Batu dengan nilai $\mathrm{F}$ hitung $<\mathrm{F}$ tabel ( $0,063<2,769) .2$

\section{Hipotesis}

H1: Ada pengaruh secara parsial budaya organisasi terhadap kepuasaan kerja karyawan Universitas Ahmad Dahlan

H2: Ada pengaruh secara parsial Komunikasi terhadap kepuasaan kerja karyawan Universitas Ahmad Dahlan

H3: Ada pengaruh secara parsial Lingkungan kerja terhadap kepuasaan kerja karyawan Universitas Ahmad Dahlan
H4: Ada pengaruh secara simultan antara budaya organisasi, komunikasi dan lingkungan kerja terhadap kepuasaan kerja karyawan Universitas Ahmad Dahlan

\section{METODE PENELITIAN}

\section{Populasi dan Sampel}

Menurut Sugiyono

(2014:115)

"Populasi adalah wilayah generalisasi yang terdiri dari objek atau subjek yang mempunyai kualitas dan karakteristik tertentu yang ditetapkan oleh peneliti untuk dipelajari dan kemudian di tarik kesimpulannya. Populasi dalam penelitian ini Karyawan Fakultas yang memiliki prodi ter akreditasi A Universitas Ahmad Dahlan yang berjumlah 65 orang.

"Sampel adalah bagian dari jumlah dan karakteristik yang dimiliki dari populasi itu dan sampel yang diambil dari populasi harus betul-betul mewakili" (Sugiyono: 116). Ukuran sampel untuk penelitian ini adalah sebagai berikut:

Bila dalam penelitian akan melakukan analisis dengan multivariate (korelasi atau regresi berganda misalnya), maka jumlah anggota sampel minimal 10 kali jumlah variable yang diteliti. Dalam penelitian ini, variable penelitian ada 4 (independen+dependen), maka minimal sampel $4 \times 10=40$ (Sugiyono, 2014)

\section{Definisi Operasional}

Variabel Independen

Budaya Organisasi $\left(\mathbf{X}_{1}\right)$

Budaya perusahaan merupakan sesuatu hal yang sangat kompleks. Untuk itu, di dalam pengukuran budaya perusahaan atau organisasi diperlukan indicator yang merupakan karakteristik dasar budaya organisasi sebagai wujud nyata keberadaanya. Berikut adalah 
indikator budaya organisasi yang dikemukakan oleh Robbins\& Coulter dalam Ardana dkk (2009), sebagai berikut:

a) Inovasi dan pengambilan resiko

b) Perhatian ke hal yang rinci atau detail

c) Orientasi hasil33

d) Orientasi orang

e) Orientasi tim

f) Keagresifan dan

g) Kemantapan/stabilitas

Berdasarkan indikator diatas saya mengambil contoh Kuesioner dari skripsi Naryanti ika (2013).

\section{Komunikasi $\left(\mathbf{X}_{2}\right)$}

Pengertian dasar komunikasi atau dalam bahasa Inggris communication berasal dari bahasa latin communication, dan bersumber dari kata communis yang berarti sama. Sama di sini maksudnya adalah sama makna. Jadi, kalau dua orang terlibat dalam komunikasi, misalnya dalam bentuk percakapan, maka komunikasi akan terjadi atau berlangsung selama kesamaan makna mengenai apa yang dipercakapkan. Menurut Effendy (2004:6) komunikasi dapat diukur dari beberapa indikator sebagai berikut:

a) Komunikator (orang yang menyampaikan pesan)

b) Pesan (pernyataan yang didukung oleh lambang)

c) Komunikan (orang yang menerima pesan)

d) Media (sarana yang mendukung pesan apabila komunikan jauh tempatnya atau banyak jumlahnya)

e) Efek (dampak sebagai pengaruh dari pesan)

Berdasarkan indikator diatas saya mengambil contoh Kuesioner dari skripsi Kurnianingsih Satia (2013).34

\section{Lingkungan kerja $\left(\mathbf{X}_{3}\right)$}

Lingkungan kerja adalah segala sesuatu yang ada di sekitar karyawan pada saat bekerja, baik yang berbentuk fisik ataupun non fisik, langsung atau tidak langsung, yang dapat mempengaruhi dirinya dan pekerjaanya saat bekerja. Yang menjadi indikator-indikator lingkungan kerja menurut Sedarmayanti (2001:46) adalah sebagai berikut :

a) Penerangan, suhu udara

b) Suhu udara

c) Suara bising

d) Penggunaan warna

e) Ruang gerak yang diperlukan

f) Keamanan kerja

g) Hubungan karyawan

Indikator a-c saya ambil dari contoh Kuesioner skripsi Pratama Aditya Nur (2016). Sedangkan indicator d-g diambil dari contoh kuesioner skripsi Mahardikawanto (2013)

\section{Variabel Dependen}

\section{Kepuasaan Kerja (Y)}

Kepuasan kerja adalah sikap umum terhadap pekerjaan seseorang yang menunjukkan perbedaan antara jumlah penghargaan yang diterima pekerjaan dan jumlah yang mereka yakini seharusnya mereka terima. Menurut As'ad (2004) indikator yang mempengaruhi kepuasan kerja yaitu:

a) Kepuasaan Finansial

b) Kepuasaan Fisik

c) Kepuasaan Sosial

d) Kepuasaan Psikologi

Bersasarkan Indikator diatas saya mengambil contoh Kuesioner dari skripsi Yusuf Reza Firgiawan (2017).

\section{Uji Instrumen}

1. Uji Validitas

Uji validitas adalah uji yang dilakukan untuk memastikan kemampuan sebuah skala untuk mengukur konsep yang dimaksudkan. Manfaat dari uji validitas yaitu untuk mengetahui apakah item-item yang ada 
dalam kuesioner benar-benar mampu mengungkapkan dengan pasti apa yang akan diteliti. Uji validitas dilakukan untuk mengetahui kemampuan instrumen dalam mengukur variabel penelitian. Pengujian ini dilakukan dengan mengajukan butir-butir pertanyaan kuesioner yang nantinya akan diberikan kepada responden. Setelah mendapatkan data dari responden kemudian dilakukan uji construct validity dengan menggunakan product moment yang memudahkan dalam melakukan uji validitas, maka digunakan analisis faktor yang ada pada program komputer SPSS 20. Item-item yang mengukur konsep yang sama akan memiliki korelasi yang tinggi dan berkorelasi rendah dengan item-item yang mengukur konsep yang berbeda (Ghozali, 2011). Hal ini ditunjukkan dengan muatan faktor item yang tinggi pada satu faktor yang seharusnya diukur saja dan bermuatan faktor rendah pada faktor rendah yang diukur oleh itemitem.

\section{Uji Reliabilitas}

Reliabilitas menunjukkan konsistensi dan stabilitas dari suatu skor (skala pengukuran). Hasil pengukuran dapat dipercaya bila dalam beberapa kali pelaksanaan pengukuran terhadap kelompok subyek yang sama diperoleh hasil yang relatif sama, selama aspek yang diukur tidak berubah. Uji reliabilitas pada penelitian ini menggunakan metode Cronbach Alpha untuk menentukan apakah setiap instrumen reliabel atau tidak. Pengukuran ini menggunakan uji statistik Cronbach Alpha. Penghitungan Cronbachs alpha akan dilakukan dengan menggunakan bantuan program SPSS 20. Suatu konstruk atau variabel dikatakan reliabel jika memberikan nilai Cronbach Alpha > 0.60 diterima (Ghozali, 2011).

\section{Teknik Analisis Data}

1. Analisis Regresi Berganda

Analisis regregsi pada dasarnya dilakukan untuk mengetahui kekuataan hubungan antara dua variabel atau lebih (Ghozali, 2013:79). Dengan menggunakan analisis regresi berganda dapat diketahui variabel independent Budaya Organisasi (X1), Komunikasi (X2), Lingkungan Kerja (X3) dan Kepuasaan Kerja (Y). Adapun rumus untuk menghitung regresi berganda adalah sebagai berikut:

$\mathrm{Y}=\mathrm{a}+\mathrm{b} 1 \mathrm{X} 1+\mathrm{b} 2 \mathrm{X} 2+\mathrm{b} 3 \mathrm{X} 3+\mathrm{e}$

Keterangan:

$\mathrm{Y}=$ Kepuasan kerja karyawan (Variabel dependen)

$\mathrm{a}=$ Konstanta

$\mathrm{b}=$ Koefisien

$\mathrm{X}_{1}=$ Variabel (Independen) Budaya Organisasi

$\mathrm{X}_{2}=$ Variabel (Independen) Komitmen Organisasi

$\mathrm{X}_{3}=$ Variabel (Independen) Stres Kerja

$\mathrm{e}=$ Standar Error

\section{Uji Hipotesis}

\section{Uji Parsial (Uji T)}

Uji Signifikan Pengaruh Parsial (Uji t)

Uji t digunakan untuk menguji signifikasi pengaruh parsial dan independent terhadap variabel dependent. Uji statistik $\mathrm{t}$ pada dasarnya menunjukan seberapa jauh pengaruh suatu variabel independen secara individual dalam menerangkan variabel dependen (Ghozali 2011). Kesimpulan yang diambil dalam uji t ini adalah dengan melihat signifikansi $(\alpha)$ dengan ketentuan:

1) Perumusan Hipotesis.

$\mathrm{H} 0=\alpha>5 \%$ (tidak ada pengaruh yang signifikan) 
$\mathrm{Ha}=\alpha<5 \%$ (ada pengaruh yang signifikan)

2) Penentuan nilai kritis

Menggunakan tingkat kepercayaan 95\% dengan tingkat signifikansi $(\alpha: 0,05)$ dan $\mathrm{df}=(\mathrm{n}-2)$.

3) Terima, jika t hitung $\leq t$ table Tolak, jika t hitung $>\mathrm{t}$ table

4) Pengambilan Keputusan.

\section{Uji Simultan (Uji F)}

Uji $F$ dimaksudkan untuk menguji tingkat signifikan pengaruh variabelvariabel independent $X$ secara keseluruhan terhadap variabel dependent Y. Uji $F$ pada dasarnya menunjukan apakah semua variabel independen atau bebas yang dimasukan dalam model mempunyai pengaruh secara bersamasama terhadap variabel dependen/terikat (Ghozali, 2011). Dalam uji F kesimpulan yang diambil adalah dengan melihat signifikansi $(\alpha)$ dengan ketentuan:

$\mathrm{H} 0=\alpha>5 \%$ (tidak ada pengaruh yang signifikan)

$\mathrm{Ha}=\alpha<5 \%$ (ada pengaruh yang signifikan).

\section{Uji Koefisien Determinasi}

Uji Koefisien determinasi pada intinya mengukur seberapa jauh kemampuan model dalam menerangkan variasi variabel dependen. Nilai koefisien determinasi adalah antara nol dan satu. Nilai R2 yang kecil berarti kemampuan variabel-variabel independen dalam menjelaskan variasi variabel dependen sangat terbatas. Nilai R2 yang mendekati satu berarti variabelvariabel independen memberikan hampir semua informasi yang dibutuhkan untuk memprediksi variasi variabel dependen (Ghozali, 2011). Secara umum koefisien determinasi untuk data silang (crosssection) relatif rendah karena adanya variasi yang besar antara masing-masing pengamatan, sedangkan untuk data runtun waktu (time series) biasanya mempunyai nilai koefisien determinasi yang tinggi.

\section{HASIL PENELITIAN DAN PEMBAHASAN}

\section{Hasil Analisis Responden}

Observasi data responden ini adalah untuk mengetahui karakteristik responden setelah mereka mengisi angket yang diberikan. Hasil penelitian yang didapatkan adalah :

1. Jenis Kelamin

2. Pendidikan terakhir

3. Masa Bekerja

4. Pendapatan perbulan

Untuk mengetahui karakteristik responden dari angket yang disebarkan. Dalam penelitian ini hasil yang diperoleh adalah sebagai berikut:

\begin{tabular}{|c|c|c|c|}
\hline & & & \\
\hline No & Jenis Kelamin & Jumlah karyawan & Persentase \% \\
\hline 1 & Laki-laki & 25 & 38,5 \\
\hline \multirow[t]{2}{*}{2} & Perempuan & 40 & 61,5 \\
\hline & Total & 65 & 100 \\
\hline No & Pendidikan & Jumlah karyawan & Persentase \% \\
\hline 1 & Diploma/D3 & 24 & 36,9 \\
\hline 2 & S1 & 40 & 61,5 \\
\hline \multirow[t]{2}{*}{3} & S2 & 1 & 1,5 \\
\hline & Total & 65 & 100 \\
\hline No & Masa Bekerja & Jumlah karyawan & Persentase \% \\
\hline 1 & $\mathrm{Mk} \leq 5$ tahun & 33 & 50,8 \\
\hline 2 & $5 \mathrm{Mk} \leq 15$ tahun & 16 & 24,6 \\
\hline 3 & 15 tahun $\leq 25$ tahun & 10 & 15,4 \\
\hline \multirow[t]{2}{*}{4} & $\mathrm{Mk} \geq 25$ tahun & 6 & 9,2 \\
\hline & Total & 65 & 100 \\
\hline No & Gaji & Jumlah karyawan & Persentase \% \\
\hline 1 & $\leq \mathrm{Rp} 2.000 .000$ & 12 & 18,5 \\
\hline 2 & $2.100 .000-3.000 .000$ & 27 & 41,5 \\
\hline 3 & $3.100 .000-5.000 .000$ & 26 & 40 \\
\hline \multirow[t]{2}{*}{4} & $\geq \operatorname{Rp} 5.000 .000$ & - & - \\
\hline & Total & 65 & 100 \\
\hline
\end{tabular}




\section{Hasil Penelitian}

1. Hasil Uji Validitas

\begin{tabular}{|c|c|c|c|c|}
\hline No Item & Pernyataan & Rhitung & Rtabel (63) & Keterangan \\
\hline 1 & BO1 & 0,674 & 0,244 & VALID \\
\hline 2 & BO2 & 0,340 & 0,244 & VALID \\
\hline 3 & BO3 & 0,189 & 0,244 & TIDAK VALID \\
\hline 4 & BO4 & 0,715 & 0,244 & VALID \\
\hline 5 & BO5 & 0,606 & 0,244 & VALID \\
\hline 6 & BO6 & 0,638 & 0,244 & VALID \\
\hline 7 & BO7 & 0,306 & 0,244 & VALID \\
\hline 8 & BO8 & 0,539 & 0,244 & VALID \\
\hline 9 & BO9 & 0,645 & 0,244 & VALID \\
\hline 10 & BO10 & 0,324 & 0,244 & VALID \\
\hline 11 & BO11 & 0,661 & 0,244 & VALID \\
\hline 12 & BO12 & 0,654 & 0,244 & VALID \\
\hline 13 & BO13 & 0,664 & 0,244 & VALID \\
\hline 14 & BO14 & 0,610 & 0,244 & VALID \\
\hline 15 & BO15 & 0,574 & 0,244 & VALID \\
\hline 16 & BO16 & 0,594 & 0,244 & VALID \\
\hline 17 & BO17 & 0,779 & 0,244 & VALID \\
\hline 19 & BO18 & 0,713 & 0,244 & VALID \\
\hline 19 & BO19 & 0,787 & 0,244 & VALID \\
\hline
\end{tabular}

b) Uji Validitas 2 variabel Budaya Organisasi

\begin{tabular}{|c|c|c|c|c|}
\hline No Item & Pernyataan & Rhitung & Rtabel (63) & Keterangan \\
\hline 1 & BO1 & 0,672 & 0,244 & VALID \\
\hline 2 & $\mathrm{BO} 2$ & 0,339 & 0,244 & VALID \\
\hline
\end{tabular}

\begin{tabular}{|c|c|c|c|c|}
\hline 3 & $\mathrm{BO} 4$ & 0,719 & 0,244 & VALID \\
\hline 4 & $\mathrm{BO} 5$ & 0,596 & 0,244 & VALID \\
\hline 5 & $\mathrm{BO} 6$ & 0,634 & 0,244 & VALID \\
\hline 6 & $\mathrm{BO} 7$ & 0,300 & 0,244 & VALID \\
\hline
\end{tabular}

\begin{tabular}{|c|c|c|c|c|}
7 & BO8 & 0,554 & 0,244 & VALID \\
\hline 8 & BO9 & 0,649 & 0,244 & VALID \\
\hline
\end{tabular}

\begin{tabular}{|c|c|c|c|c|}
8 & BO9 & 0,649 & 0,244 & VALID \\
\hline 9 & BO10 & 0,324 & 0,244 & VALID \\
\hline 10 & BO11 & 0,664 & 0,244 & VALID \\
\hline
\end{tabular}

\begin{tabular}{|c|c|c|c|c|}
\hline 10 & BO11 & 0,664 & 0,244 & VALID \\
\hline 11 & BO12 & 0,655 & 0,244 & VALID \\
\hline 12 & BO13 & 0,672 & 0,244 & \\
\hline
\end{tabular}

\begin{tabular}{|c|c|c|c|c|}
\hline 12 & BO13 & 0,672 & 0,244 & VALID \\
\hline 13 & BO14 & 0,606 & 0,244 & VALID \\
\hline 14 & BO15 & 0,582 & 0,244 & VALID \\
\hline
\end{tabular}

\begin{tabular}{|c|c|c|c|c|}
\hline 14 & BO15 & 0,582 & 0,244 & VALID \\
\hline 15 & BO16 & 0,594 & 0,244 & VALID \\
\hline 16 & BO17 & 0,789 & 0,244 & VALID \\
\hline 17 & BO18 & 0,703 & 0,244 & VALID \\
\hline 18 & BO19 & 0,793 & 0,244 & VALID \\
\hline
\end{tabular}

Dari data output uji validitas variabel Budaya Organisasi, setelah dilakukan 2kali uji validitas peneliti dapat menyimpulkan bahwa ke-19 pernyataan, ada 1 pernyataan tidak valid. Pernyataan yang tidak valid yaitu
BO3. Hal ini dapat dilihat nilai $r$ hitung (Pearson Correlation) yang di dapat ternyata lebih kecil dari rtabel

Uji validitas 1 variabel Komunikasi

\begin{tabular}{|c|c|c|c|c|}
\hline No Item & Pernyataan & Rhitung & Rtabel (63) & Keterangan \\
\hline 1 & $\mathrm{~K} 1$ & 0,674 & 0,244 & VALID \\
\hline 2 & $\mathrm{k} 2$ & 0,546 & 0,244 & VALID \\
\hline 3 & $\mathrm{~K} 3$ & 0,758 & 0,244 & VALID \\
\hline 4 & $\mathrm{~K} 4$ & 0,758 & 0,244 & VALID \\
\hline 5 & $\mathrm{~K} 5$ & 0,733 & 0,244 & VALID \\
\hline 6 & $\mathrm{~K} 6$ & 0,749 & 0,244 & VALID \\
\hline 7 & $\mathrm{~K} 7$ & 0,591 & 0,244 & VALID \\
\hline 8 & $\mathrm{~K} 8$ & 0,757 & 0,244 & VALID \\
\hline 9 & $\mathrm{~K} 9$ & 0,745 & 0,244 & VALID \\
\hline 10 & $\mathrm{~K} 10$ & 0,597 & 0,244 & VALID \\
\hline
\end{tabular}

Dari data output uji validitas variabel Komunikasi, setelah dilakukan 2kali uji validitas peneliti dapat menyimpulkan bahwa ke-10 pernyataan, semua pernyataan dikatakan valid. Hal ini dapat dilihat nilai rhitung (Pearson Correlation) yang di dapat ternyata lebih kecil dari rtabel.

Uji validitas 1 variabel Lingkungan Kerja

\begin{tabular}{|c|c|c|c|c|}
\hline No Item & Pernyataan & Rhitung & Rtabel (63) & Keterangan \\
\hline 1 & LK1 & 0,756 & 0,244 & VALID \\
\hline 2 & LK2 & 0,741 & 0,244 & VALID \\
\hline 3 & LK3 & 0,769 & 0,244 & VALID \\
\hline 4 & LK4 & 0,789 & 0,244 & VALID \\
\hline 5 & LK5 & 0,614 & 0,244 & VALID \\
\hline 6 & LK6 & 0,774 & 0,244 & VALID \\
\hline 7 & LK7 & 0,473 & 0,244 & VALID \\
\hline 8 & LK8 & 0,496 & 0,244 & VALID \\
\hline 9 & LK9 & 0,465 & 0,374 & VALID \\
\hline 10 & LK10 & 0,765 & 0,244 & VALID \\
\hline 11 & LK11 & 0,698 & 0,244 & VALID \\
\hline 12 & LK12 & 0,612 & 0,244 & VALID \\
\hline 13 & LK13 & $\begin{array}{l}0,599 \\
0.244\end{array}$ & VALID \\
\hline 14 & LK14 & 0,723 & 0,244 & VALID \\
\hline
\end{tabular}

Dari data output uji validitas variabel Lingkungan Kerja, setelah dilakukan 2 kali uji validitas peneliti dapat menyimpulkan bahwa ke-14 pernyataan, semua pernyataan dikatakan valid. Hal ini dapat dilihat nilai rhitung (Pearson 
Correlation) yang di dapat ternyata lebih kecil dari rtabel.

Uji validitas 1 variabel Kepuasaan Kerja

\begin{tabular}{|c|c|c|c|c|}
\hline No Item & Pernyataan & Rhitung & Rtabel (63) & Keterangan \\
\hline 1 & KK1 & 0,673 & 0,244 & VALID \\
\hline 2 & KK2 & 0,736 & 0,244 & VALID \\
\hline 3 & KK3 & 0,630 & 0,244 & VALID \\
\hline 4 & KK4 & 0,642 & 0,244 & VALID \\
\hline 5 & KK5 & 0,792 & 0,244 & VALID \\
\hline 6 & KK6 & 0,778 & 0,244 & VALID \\
\hline 7 & KK7 & 0,762 & 0,244 & VALID \\
\hline 8 & KK8 & 0,727 & 0,244 & VALID \\
\hline 9 & KK9 & 0,711 & 0,244 & VALID \\
\hline 10 & KK10 & 0,673 & 0,244 & VALID \\
\hline
\end{tabular}

Dari data output uji validitas variabel Kepuasaan Kerja, setelah dilakukan 2kali uji validitas peneliti dapat menyimpulkan bahwa ke-10 pernyataan, semua pernyataan dikatakan valid. Hal ini dapat dilihat nilai rhitung (Pearson Correlation) yang di dapat ternyata lebih kecil dari rtabel

2. Hasil Uji Reliabilitas

\begin{tabular}{|c|l|c|c|}
\multicolumn{5}{|c|}{ Tabel Uji Reliabilitas dengan Instrumen Penelitian } \\
\hline NO & \multicolumn{1}{|c|}{ Pernyataan } & Cronbach's Alpha & Keterangan \\
\hline 1 & Budaya Organisasi & 0,901 & Reliabel \\
\hline 2 & Komunikasi & 0,897 & Reliabel \\
\hline 3 & Lingkungan Kerja & 0,908 & Reliabel \\
\hline 4 & Kepuasaan Kerja & 0,909 & Reliabel \\
\hline \multicolumn{4}{|c|}{ Sumber: Data Primer vang diolah 2019 } \\
\hline
\end{tabular}

Jika dilihat dari tabel 5.3, maka terlihat bahwa empat komponen variabel (Cronbach's Alpha) diatas menunjukkan nilai variable Budaya Organisasi sebesar $0,901>0,600$ variable Komunikasi sebesar 0,897 > 0,600 variable Lingkungan Kerja sebesar 0,908 > 0,600 dan variable Kepuasaan Kerja sebesar 0,909 > 0,600 maka dapat disimpulkan bahwa keseluruhan instrumen yang dipakai dalam variable diatas adalah handal atau reliable.
3. Hasil Uji Regresi Linier Berganda Tabel Uji Regresi Berganda

Coefficients

\begin{tabular}{|c|c|c|}
\hline \multirow{2}{*}{ Model } & $\begin{array}{l}\text { Unstandardized } \\
\text { Coefficients }\end{array}$ & \multirow[b]{2}{*}{ Sig. } \\
\hline & B & \\
\hline $1 \quad$ (Constant) & 0,270 & 0,315 \\
\hline X1 (Budaya Organisasi) & $-0,033$ & 0,807 \\
\hline $\mathrm{X} 2$ (Komunikasi) & 0,246 & 0,024 \\
\hline X3 (Lingkungan Kerja) & 0,680 & 0,000 \\
\hline
\end{tabular}

a. Dependent Variabel: Y

Dari tabel diatas diketahui bahwa dari hasil tersebut dapat dibuat persamaan regresi sebagai berikut:

Unstandardized Beta Coefficients:

Dari ketiga variabel independen yang dimasukkan ke dalam model, regresi varibael Budaya Organisasi tidak signifikan. Hal ini dapat dilihat dari probabilitas signifikansi untuk Budaya Organisasi sebesar 0,807 dan itu jauh diatas 0,05. Sedangkan Komunikasi dan Lingkungan Kerja signifikansi pada 0,05. Dari sini dapat disimpulkan bahwa variabel Kepuasaan Kerja karyawan dipengaruhi oleh Komunikasi dan Lingkungan Kerja dengan persamaan maatematis:

$\mathrm{Y}=\mathrm{a}+\mathrm{b} 1 \mathrm{X} 1+\mathrm{b} 2 \mathrm{X} 2+\mathrm{b} 3 \mathrm{X} 3$

Kepuasaan Kerja $=0,270+0,033 X 1+0$, $246 \mathrm{X} 2+0,680 \mathrm{X} 3+\mathrm{e}$ 
4. Hasil Uji Parsial (Uji T)

Tabel Hasil Uji t

Coefficients

\begin{tabular}{|c|c|}
\hline Model & $t$ \\
\hline $1 \quad$ (Constant) & 1,013 \\
\hline X1 (Budaya Organisasi) & $-0,246$ \\
\hline X2 (Komunikasi) & 2,308 \\
\hline X3 (Lingkungan Kerja) & 5,725 \\
\hline
\end{tabular}

Pengaruh Variabel Budaya Organisasi terhadap Kepuasaan Kerja

a) Berdasarkan hasil perhitungan dengan program software SPSS (Statistical Product and Service Solution) 20.0 for windows diperoleh nilai t hitung adalah 0,246 dan $\mathrm{t}$ tabel 1,669 maka $\mathrm{t}$ hitung $<\mathrm{t}$ tabel $(-0,246<1,669)$. Sehingga dapat diambil kesimpulan adalah $\mathrm{H} 0$ diterima dan H1 ditolak, yang berarti variabel Budaya Organisasi (X1) tidak berpengaruh signifikan terhadap Kepuasaan59 Kerja (Y) Karyawan Tata Usaha Universitas Ahmad Dahlan Yogyakarta. Hasil penelitian ini terdukung dan sejalan dengan penelitian Elvitrianim Purba (2016) yang menyatakan bahwa Budaya organisasi tidak berpengaruh terhadap Kepuasaan kerja karyawan. Alasan tidak signifikan adanya beberapa indicator budaya organisasi yang tidak sesuai dengan indicator kepuasaan kerja sehingga variabel tidak saling berkaitan.

b) Pengaruh Variabel Komunikasi terhadap Kepuasaan Kerja

Berdasarkan hasil perhitungan dengan program software SPSS (Statistical Product and Service Solution) 20.0 for windows diperoleh nilai $t$ hitung adalah
2,308 dan $\mathrm{t}$ tabel 1,669 maka $\mathrm{t}$ hitung $>\mathrm{t}$ tabel $(2,308>1,669)$. Sehingga dapat diambil kesimpulan adalah $\mathrm{H0}$ ditolak dan $\mathrm{H} 2$ diterima, yang berarti variabel Komunikasi (X2) berpengaruh signifikan terhadap variabel Kepuasaan Kerja (Y) Karyawan Tata Usaha Universitas Ahmad Dahlan Yogyakarta. Hasil penelitian ini terdukung sejalan dengan penelitian Dewi Kurniawati (2008) yang menyatakan bahwa Komunikasi berpengaruh signifikan terhadap Kepuasaan Kerja karyawan.

c) Pengaruh Variabel Lingkungan Kerja terhadap Kepuasaan Kerja

Berdasarkan hasil perhitungan dengan program software SPSS (Statistical Product and Service Solution) 20.0 for windows diperoleh nilai thitung adalah 5,725 dan ttabel 1,669 maka $\mathrm{t}$ hitung $>\mathrm{t}$ tabel $(5,725>1,669)$. Sehingga dapat diambil kesimpulan adalah H0 ditolak, dan H3 diterima, yang berarti variabel Lingkungan Kerja (X3) berpengaruh signifikan terhadap variabel Kepuasaan Kerja (Y) Karyawan Tata Usaha Universitas Ahmad Dahlan Yogyakarta. Hasil penelitian ini terdukung sejalan dengan penelitian Suryaningsih Ni Putu Eka Putri (2013) yang menyatakan bahwa Komunikasi berpengaruh signifikan terhadap Kepuasaan Kerja karyawan.

5. Hasil Uji Simultan (Uji F)

\begin{tabular}{|c|c|c|}
\multicolumn{3}{|c|}{ Tabel Hasil Uji F } \\
\hline Model & F & Sig. \\
\hline Regression & 28,143 & $0,000^{\mathrm{a}}$ \\
& & \\
\hline
\end{tabular}

Kesimpulan

Berdasarkan Hasil Uji Regresi Simultan (Uji F) yang terdapat pada tabel 5.7 diketahui bahwa nilai $\mathrm{F}$ hitung menunjukkan nilai sebesar 28,143 dan nilai signifikansi $F$ sebesar 0,000 . Jadi $F$ hitung $>\mathrm{F}$ tabel $(28,143>2,75)$ atau sig $\mathrm{F}<5 \%(0,000<0,05)$. Kesimpulan 
yang dapat diambil adalah $\mathrm{H} 0$ ditolak dan $\mathrm{H} 4$ diterima yang berarti bahwa terdapat pengaruh yang signifikan dari variabel Budaya Organisasi (X1) Komunikasi (X2) Lingkungan Kerja (X3) secara bersama-sama terhadap Kepuasaan Kerja (Y)

\section{Hasil Uji Koefisien Determinasi}

Tabel Hasil Uji Determinasi

\begin{tabular}{|c|c|}
\hline Model & R Square \\
\hline 1 & 0,581 \\
\hline
\end{tabular}

Koefisien Determinasi

$\left(\mathrm{R}^{2}\right)$

menunjukkan seberapa besar presentase variabel independen yang digunakan dalam model mampu menjelaskan variasi dalam variabel dependen. Dari tabel 5.8 diperoleh angka $\mathrm{R}^{2}$ (R Square) sebesar $0,581 \quad(58,1 \%)$. Hal ini menunjukkan bahwa presentase sumbangan pengaruh variabel independen (variabel Budaya Organisasi, Komunikasi, Lingkungan Kerja) terhadap variabel dependen (Kepuasaan Kerja) sebesar 58,1\% atau dengan kata lain variabel independen yang digunakan dalam model mampu menjelaskan sebesar 58,1\% variabel dependen yaitu Kepuasaan Kerja, sedangkan sisanya sebesar $41,9 \%$ dipengaruhi atau dijelaskan oleh variabel lain yang tidak dimasukkan dalam penelitian ini.

\section{KESIMPULAN DAN SARAN}

\section{Kesimpulan}

Penelitian ini bertujuan untuk mengetahui pengaruh budaya organisasi, komunikasi dan lingkungan kerja terhadap kepuasaan kerja karyawan. Responden dalam penelitian ini berjumlah 65 orang. Berdasarkan analisis hasil penelitian dan pembahasan yang telah dilakukan maka dapat ditarik kesimpulan sebagai berikut:

1. Variabel budaya organisasi tidak berpengaruh signifikan terhadap kepuasaan kerja karyawan tata usaha Universitas Ahmad Dahlan dengan nilai signifikan 0,807 . Hal ini menunjukkan bahwa budaya organisasi (X1) tidak berpengaruh signifikan terhadap kepuasaan kerja karyawan (Y) Universitas Ahmad Dahlan Yogyakarta.

2. Variabel komunikasi terbukti berpengaruh signifikan terhadap kepuasaan kerja karyawan tata usaha Universitas Ahmad Dahlan dengan nilai signifikan 0,024. Hal ini menunjukkan bahwa komunikasi (X2) terbukti berpengaruh signifikan terhadap kepuasaan kerja karyawan tata usaha Universitas Ahmad Dahlan Yogyakarta.

3. Variabel lingkungan kerja terbukti berpengaruh signifikan terhadap kepuasaan kerja karyawan tata usaha Universitas Ahmad Dahlan dengan nilai signifikan 0,000 . Hal ini menunjukkan bahwa lingkungan kerja (X3) terbukti berpengaruh signifikan terhadap kepuasaan kerja karyawan tata usaha Universitas Ahmad Dahlan Yogyakarta.

4. Hasil dari olah data uji $F$ yang dilakukan, maka dapat disimpulkan bahwa budaya organisasi, komunikasi dan lingkungan kerja secara bersamasama (simultan) berpengaruh kepuasan kerja. Hal ini dibuktikan dengan hasil analisis uji $\mathrm{F}$ yang63 menunjukkan bahwa nilai signifikansi dari hasil olah data lebih kecil dari tingkat signifikansi yang ditentukan yaitu $0,000<0,05$, maka $\mathrm{H} 4$ diterima. 


\section{Saran}

Berdasarkan kesimpulankesimpulan yang ditarik oleh peneliti, maka ada beberapa saran yang peneliti sampaikan kepada instansi terkait. Saran yang disampaikan :

\section{Bagi Manajemen}

Dengan melihat hasil yang didapatkan maka Karyawan Tata Usaha Universitas Ahmad Dahlan hendaknya bisa meningkatkan budaya organisasi untuk kepuasaan kerja karyawan tata usaha Universitas Ahmad Dahlan. Oleh karena itu, saran bagi Manajer Universitas Ahmad Dahlan yang ingin peneliti sampaikan yaitu untuk meningkatkan budaya organisasi agar lebih bisa memperhatikan indikator yang terjadi seperti Orientasi hasil, Orientasi orang, Orientasi tim, Keagresifan, Stabilitas. Oleh karena itu sebaiknya petinggi Universitas Ahmad Dahlan mengadakan program family gathering yang menunjang kekuatan batin dalam organisasi setiap karyawan tata usaha di semua prodi. Komunikasi yang ada didalam karyawan tata usaha Universitas Ahmad Dahlan untuk ditingkatkan terutama memperhatikan indikator sebagai berikut komunikator, Pesan, Komunikan, media dan efek. Oleh karena itu sebaiknya menjaga konsistensi komunikasi yang sudah ada di tata usaha Universitas Ahmad dahlan dan membangun sistem komunikasi yang baik seperti memaksimalkan komunikasi antar karyawan lebih baik dan lebih mudah dimengerti. Lingkungan Kerja yang sudah ada di Universitas Ahmad Dahlan mungkin sudah baik. Sebaiknya memperhatikan beberapa indikator lingkungan kerja seperti ruang gerak,64 keamanan dan hubungan karyawan. Oleh karena itu lingkungan kerja yang sudah ada di jaga dan dipertahankan agar karyawan merasa lebih nyaman dan aman dalam bekerja.

2. Bagi Peneliti Berikutnya

Dalam penelitian ini, variabel independen (Budaya Organisasi, Komunikasi dan Lingkungan kerja) yang digunakan hanya menghasilkan R2 (R Square) sebesar 0,581 $(58,1 \%)$. Oleh karena itu saran bagi peneliti berikutnya sebaiknya memikirkan juga variabelvariabel lain, seperti stress kerja, kecerdasan emosional, disiplin, motivasi, dan kompensasi. Selain itu sebaiknya perlu pertimbangan untuk menggunakan variabel-variabel yang sudah peneliti sebutkan sebelumnya, serta memperhatikan indikator-indikator dari variabel tersebut agar mengetahui pengaruhnya terhadap kepuasaan kerja.

\section{DAFTAR PUSTAKA}

Alex S .Nitisemito. 2000. Manajemen Personalia: Manajemen Sumber Daya Manusia, Ed.3. Jakarta: Ghalia Indonesia.

Alex. S. Nitisemito. 2002. Manajemen Personalia. Edisi Revisi, Penerbit Ghalia Indonesia.

Algifari. 2003. Statiska Induktif untuk Ekonomi dan Bisnis. Yogyakarta: AM YKPN.

Ardana, Komang, Ni Wayan Mujiati, dan I Wayan Mudiarthan Utama. 2012. Manajemen Sumber

Daya Manusia. Yogyakarta: Graha Ilmu.

As'ad, Moh. (2004). Psikologi Industri Seri Ilmu SDM Edisi Keempat. Yogyakarta: Liberty. 
Effendy Onong Uchjana. 2004. Ilmu Komunikasi dan Teori Praktik. Bandung: PT Remaja Rosdakarya

Gibson, James,L. 2000. Organisasi, Perilaku, Struktur dan Proses. Edisi ke-5. Cetakan ke-3. Jakarta: Penerbit Erlangga.

Ghozali, Imam. 2005. Teori, Konsep, dan Aplikasi. Semarang: Badan Penerbit UniversitasDiponegoro.

Ghozali, Imam. 2013. Aplikasi Analisis Multivariate dengan Program IBM SPSS 21 Update PLS Regresi. Semarang: Badan Penerbit Universitas Diponegoro.

Handoko, T. Hani. 2004. Manajemen Personalia dan Sumberdaya Manusia. BPFE Yogyakarta: edisi kedua.

Ivancevich, John M., dkk, 2007. Perilaku dan Manajemen Organisasi, Edisi Ketujuh, Jilid2, Jakarta: Penerbit Erlangga.

Kurniawati, Dewi. 2006. Pengaruh Komunikasi terhadap Kepuasaan Kerja Karyawan pada KPRI Universitas Brawijaya Malang. Skripsi. Malang: Universitas Islam Negeri (UIN).

Kurnianingsih, Satia. 2013. Pengaruh Komunikasi vertical ke bawah antara Manajer Perencanaan ke Staff terhadap Kinerja karyawan di PT Tirta Multi Bahagia (CLUB). Skripsi. Semarang: Universitas Katolik Soegijapranata.
Mahardikawanto. 2013. Pengaruh Disiplin Kerja, Lingkungan Kerja dan kualitas kehidupan kerja terhadap Kinerja karyawan RSUD Dr. M. Ashari Pemalang. Skripsi. Semarang: Universitas Negeri Semarang.

Martoyo, Susilo. 2000. Manajemen Sumber Daya Manusia. Yogyakarta: BPFEYogyakarta.

Moch, Nazir. (2003). Metode Penelitian. Jakarta: Salemba Empat.

Moekijat, 2000. Kamus Manajemen. Bandung : Penerbit CV. Mandar Maju.

Naryanti, Ika. 2013. Analisis Pengaruh Motivasi Kerja, Kepemimpinan dan Budaya Organisasi terhadap Kinerja Karyawan CV. Kharisma Jaya Surabaya. Skripsi. Surabaya: Universitas Katholik Widya Mandala.

Notoatmodjo S., 2002. Metodologi Penelitian Kesehatan. Jakarta: PT Rineka Cipta.

Pace R. Wayne \& Faules F. Don. 2006. Komunikasi Organisasi. Bandung: PT Remaja Rosdakarya

Pratama, Aditya Nur. 2013. Pengaruh Lingkungan Kerja dan Disiplin kerja terhadap Kinerja Karyawan PT Razer Brothers. Skripsi. Yogyakarta: Universitas Negeri Yogyakarta.

Purba, Elvitrianim. 2016. "Pengaruh Budaya Organisasi terhadap Kepuasaan Kerja Pegawai PDAM 
Tirta Bina Labuhan Batu". Jurnal Stindo Profesional. Volume 6.

Robbins, Stephen P. Judge \& Timothy A. 2008. Perilaku Organisasi Buku 1. Jakarta: Salemba Empat

Sedarmayanti 2001. Sumber Daya Manusia dan Produktivitas Kerja. Bandung: Mandar Maju.

Sidanti, heny. 2015. "Pengaruh Lingkungan Kerja, Disiplin Kerja dan Motivasi Kerja terhadap

Kinerja Pegawai Negeri Sipil di Sekretariatan DPRD Kabupaten Madiun". Jurnal JIBEKA, Vol. 9, hal. 1-5.

Sobirin, Achmad. 2009. Budaya Organisasi. Sekolah Tinggi Ilmu Manajemen. YKPN: edisi kedua.

Sugiyono. 2009. Metode Penelitian Bisnis. Bandung: Alfabeta.

Sugiyono. 2014. Pendekatan Kuantitatif, Kualitatif, dan R\&D. Bandung: Alfabeta.

Suryaningsih, Ni Putu Eka Putri. 2013. "Pengaruh Budaya Organisasi, Komunikasi dan Lingkungan Kerja Fisik terhadap Kepuasaan Kerja karyawan". Jurnal Ekonomi dan Sumber Daya Manusia (Desember), hal. (94-100).

Tumbelaka Steven Set X averius, Taher Alhabsji, Umar Nimran. 2016. "Pengaruh Budaya Organisasi terhadap kepuasaan kerja, komitmen organisasional dan Intention to leave" Jurnal Bisnis dan Manajemen (Januari), hal 99-100.

Umar, Husein. 2005. Metodologi Penelitian untuk Skripsi dan Tesis Bisnis. Jakarta: Raja B Grafindo Persada.

Wibowo. 2010. Budaya Organisasi. Jakarta : PT. Raja Grafindo Persada.

Yusuf, Reza Firgiawan. 2017. Pengaruh Motivasi Ekstrinsik dan Kepuasaan Kerja terhadap Kinerja Karyawan dengan Disiplin kerja sebagai Variabel Intervening. Skripsi. Ponorogo: Universitas Muhammadiyah Ponorogo.6 